\title{
Asymmetric Arylative Dearomatization of 2,3-Disubstituted Indoles
}

Key words

dearomatization

tandem reaction

indoles

indolines

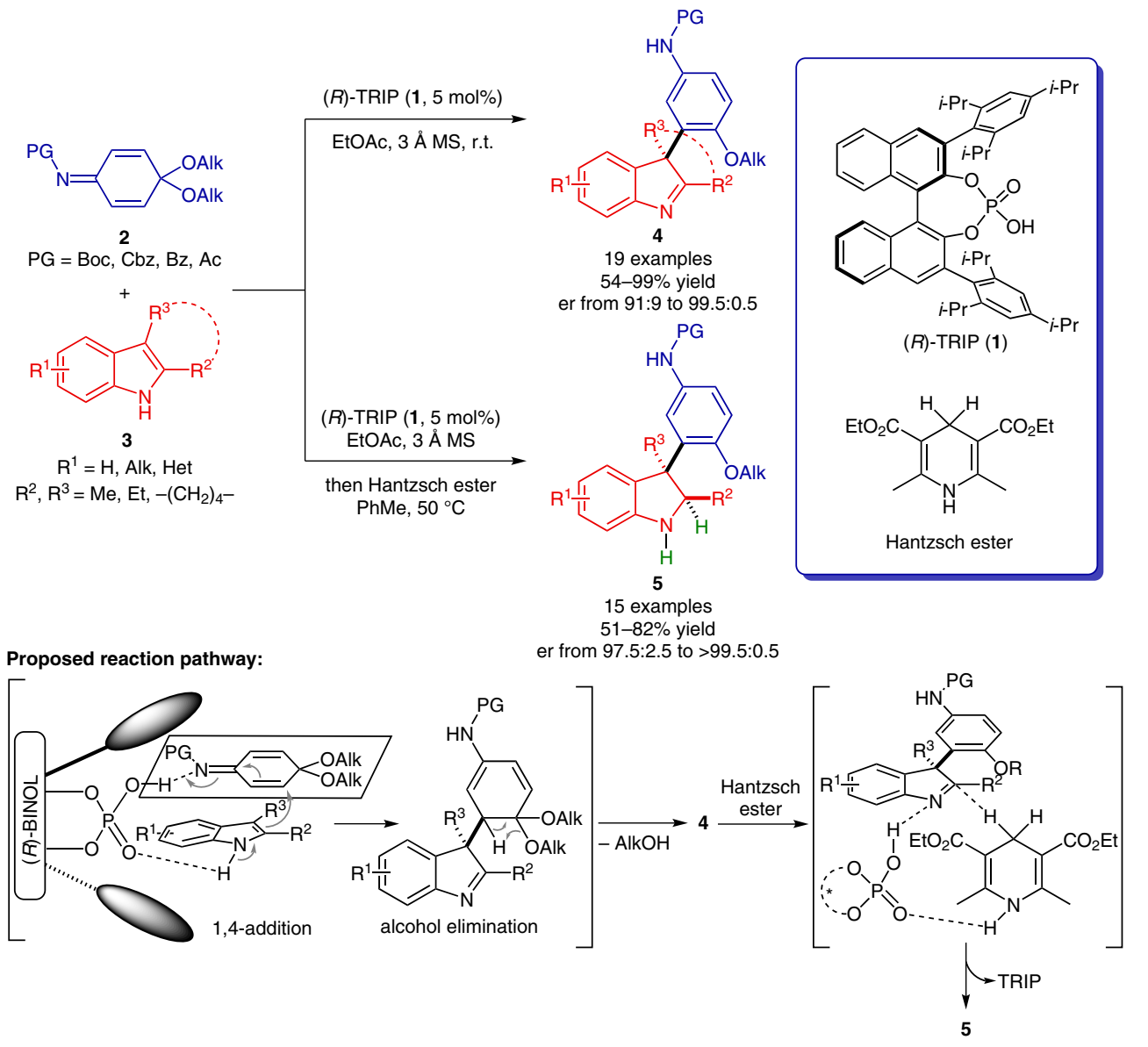

Significance: A chiral phosphoric acid catalyzed asymmetric arylative dearomatization of indoles is reported. The chiral phosphoric acid $(R)$-TRIP (1) promotes the cascade 1,4-addition-alcohol elimination of quinone imine ketals $\mathbf{2}$ and disubstituted indoles $\mathbf{3}$ to give arylation products $\mathbf{4}$. If the reaction is followed by the addition of a Hantzsch ester, a one-pot tandem arylative dearomatizationtransfer hydrogenation can be promoted to give indolines $\mathbf{5}$ possessing two consecutive stereocenters in high yields and excellent enantioselectivities.

SYNFACTS Contributors: Benjamin List, Ji Hye Kim Synfacts 2015, 11(1), 0091 Published online: 15.12.2014 Dol: 10.1055/s-0034-1379619; Reg-No.: B12114SF
Comment: The authors propose that TRIP activates the indole nucleophile and the $\alpha, \beta$-unsaturated imine electrophile through dual hydrogen bonding, promoting the enantioselective 1,4-addition, which is followed by alcohol elimination. The transfer hydrogenation step occurs with excellent diastereoselectivity, controlled by the first stereocenter. However, the enhanced enantiomeric excess of products $\mathbf{5}$ compared to products $\mathbf{4}$ is due to a kinetic resolution effect facilitated by the catalyst. 